\title{
ABORTION IN NEURAL TUBE DEFECT FRATERNITIES
}

\author{
ALISON D. MCDONALD \\ Department of Epidemiology and Health, McGill University, Montreal, Canada
}

Fraternities that include a fetus or person with a neural tube defect are remarkable for a high rate of recurrence of this type of malformation, about seven to eight times the overall rate (Record and McKeown, 1950; MacMahon, Pugh, and Ingalls, 1953; Carter, David, and Laurence, 1968) and a higher than average rate of abortions (Murphy, 1940; Record and McKeown, 1950). Murphy (1940) found that abortion or stillbirth was more frequent in the pregnancy immediately preceding neural tube defects than in the other pregnancies, and Record and McKeown (1950) observed a higher rate of abortion or infant death in this pregnancy. If abortions were related chronologically to neural tube defects in this manner one would suspect an aetiological connexion between the two. If, on the other hand, the excess of abortions were accounted for by defective fetuses, one would expect to find them randomly distributed in relation to each other within fraternities, as are births with neural tube defects (Milham, 1963). It seemed worth studying a further series of fraternities that included one or more cases of anencephaly or spina bifida in order to find out whether there was a pregnancy order relationship between these defects and abortion.

In a recent survey of anencephaly and spina bifida in the Province of Quebec (Horowitz and McDonald, 1969) an effort was made to record all births with these defects during the years 1956-65. There were in all 3,574. Pregnancy histories were later obtained by public health nurses for all the mothers who could easily be found. One thousand and twelve women were interviewed, of whom 918 had one affected child, 83 had 2, 5 had 3,5 had 4, and 1 had 5 . Though the sample interviewed may well not have been wholly representative in all respects there seems no reason for thinking that they were biased in respect of the order of abortions relative to neural tube defects.
The proportion of abortions among all pregnancies other than those with the neural tube defects is shown in Table I.

TABle I

\begin{tabular}{|c|c|c|c|c|c|c|c|c|c|c|}
\hline & 1 & 2 & 3 & 4 & $\underset{5}{\operatorname{Pregn}}$ & $\underset{6}{\operatorname{lancy}}$ & $\underset{7}{\text { Order }}$ & 8 & 9 & All \\
\hline \multirow{2}{*}{$\begin{array}{l}\text { Abor- } \\
\text { tions(\%) } \\
\text { No. of } \\
\text { pregnan- } \\
\text { cies }\end{array}$} & $15 \cdot 3$ & 13.4 & $16 \cdot 1$ & 13.9 & $16 \cdot 4$ & 15.9 & 20.9 & $16 \cdot 7$ & $16 \cdot 6$ & $15 \cdot 6$ \\
\hline & 733 & 782 & 695 & 561 & 426 & 334 & 244 & 192 & 488 & 4,455 \\
\hline
\end{tabular}

The rate of abortions was thus relatively constant.

The proportion of abortions by pregnancy order 3 before and after the birth with defect is shown in $\mathbb{D}$ Table II. In this table fraternities with more thag $\vec{\varphi}$ one neural tube defect were included once for each neural tube defect.

The abortions show some variations in rate but no systematic trend or pattern and there was no evidence that they were distributed other than randomly by pregnancy order relative to neural tube defects. Therefore the findings of Murphy (1940) and $\triangle$ Record and McKeown (1950) do not appear to be $\overrightarrow{\overrightarrow{0}}$ true for abortion alone. This suggests that the excess 3 of abortions may be due to fetal death resulting from the same or related defects. An estimate of the excess abortion rate in neural tube defect fraternities is ob- $\bar{\alpha}$ tained from comparison of the overall rate of $15.6 \%$ 은 with a figure of $12.1 \%$ found in another study of 100 윽 mongol fraternities and 100 matched control fraternities recently carried out in Quebec by me in a similar $\delta$ manner. The excess of $3.5 \%$ estimated in this way agrees with the excess reported by Record and 0 McKeown (1950). The two groups of women were $>$ comparable in their average number of pregnancies (6.4 in the neural tube defects and 5.9 in the mongol $N$ study). Socioeconomic differences may have existed

TABLE II

\begin{tabular}{|c|c|c|c|c|c|c|c|c|c|c|c|c|}
\hline \multirow[b]{2}{*}{ Pregnancy order } & \multicolumn{7}{|c|}{ Before } & \multicolumn{4}{|c|}{ After } & \multirow{3}{*}{$\begin{array}{c}\text { All } \\
15 \cdot 7 \\
5,326\end{array}$} \\
\hline & -7 & -6 & -5 & -4 & -3 & -2 & -1 & +1 & +2 & +3 & +4 & \\
\hline $\begin{array}{l}\text { Abortions (\%) } \\
\text { No. of pregnancies }\end{array}$ & $\begin{array}{c}\text { or more } \\
19.0 \\
583\end{array}$ & $\begin{array}{r}14 \cdot 9 \\
221\end{array}$ & $\begin{array}{r}16 \cdot 1 \\
290\end{array}$ & $\begin{array}{r}12 \cdot 9 \\
395\end{array}$ & $\begin{array}{r}14 \cdot 6 \\
522\end{array}$ & $\begin{array}{r}17 \cdot 2 \\
673\end{array}$ & $\begin{array}{l}16 \cdot 7 \\
850\end{array}$ & $\begin{array}{r}14.9 \\
777\end{array}$ & $\begin{array}{l}17 \cdot 3 \\
463\end{array}$ & $\begin{array}{l}14 \cdot 5 \\
242\end{array}$ & $\begin{array}{r}17 \cdot 7 \\
310\end{array}$ & \\
\hline
\end{tabular}

In this table fraternities with more than one neural tube defect were included once for each neural tube defect. 
but would probably have had little effect on the rate of abortion. In fact, if this excess compared with controls were explained by defective fetuses, the overall risk of neural tube defects after one such defect in a fraternity would be of the order of $6.2 \%$ for each subsequent conception or nearly 20 times the rate in the population.

\section{SUMMARY}

Abortions are more frequent in sibships in which there is a child with a neural tube defect than in the general population. It has been reported (Murphy, 1940; Record and McKeown, 1950) that, in pregnancies immediately preceding neural tube defects, the rate of abortions was higher than in other pregnancies. In order to find out whether this was true in another and larger series, 1,012 sibships in which at least one child had anencephaly or spina bifida were investigated. There was no evidence that abortions were distributed other than randomly by pregnancy order relative to the neural tube defect. The excess of abortions was estimated to be of the order of $3.5 \%$ of all pregnancies.

I gratefully acknowledge the collaboration of Medical Officers of Health and public health nurses throughout
Quebec. The research was assisted by funds provided by a Public Health Research Grant (Project No. 604-7-606) of the Canadian National Health Grants Programme.

\section{REFERENCES}

Carter, C. O., David, P. A., and Laurence, K. M. (1968). A family study of major central nervous system malformations in South Wales. J. med. Genet., 5,81 .

Horowitz, I., and McDonald, A. D. (1969). Anencephaly and spina bifida in the Province of Quebec. Canad. med. Ass. J., 100, 748.

MacMahon, B., Pugh, T. F., and Ingalls, T. H. (1953). Anencephalus, spina bifida, and hydrocephalus: Incidence related to sex, race, and season of birth, and incidence in siblings. Brit. J. prev. soc. Med., 7,211.

Milham, S. Jr. (1963). Random distribution of affected birth ranks in anencephalic and spina bifida sibships with two affected cases. Nature (Lond.), 200, 480.

MURPHY, D. P. (1940). Congenital Malformations; A Study of Parental Characteristics with special reference to the Reproductive Process. University of Pennsylvania Press, Philadelphia.

ReCord, R. G., and McKeown, T. (1950). Congenital malformations of the central nervous system: 2 . Maternal reproductive history and familial incidence. Brit. J. soc. Med., 4, 26. 